\title{
A Review of Records Management in Organisations
}

\author{
Ramatoulie Touray \\ University of the Gambia, University Library, Kanifing Campus, Gambia \\ Email: rtouray@utg.edu.gm
}

How to cite this paper: Touray, R. (2021) A Review of Records Management in Organisations. Open Access Library Journal, 8: e8107.

https://doi.org/10.4236/oalib.1108107

Received: October 21, 2021

Accepted: December 3, 2021

Published: December 6, 2021

Copyright (C) 2021 by author(s) and Open Access Library Inc.

This work is licensed under the Creative Commons Attribution International License (CC BY 4.0).

http://creativecommons.org/licenses/by/4.0/

(c) (i) Open Access

\begin{abstract}
The study highlights the importance of records management in organizations. Various scholars dwelled on the value of records management in organisations. As highlighted in this paper the importance of records management in today's world cannot be overemphasised; records and information are the life blood of every organisation and the basis on which decisions are made. The poor management of records does not only hinder the development process of organisations but also leads to ineffectiveness and inefficiency in service delivery. Records, being personal or official, are very important in the life of an organisation. The success of any organisation depends on effective records management practice that ensures the right records are available at the right time for effective business operations. The need for proper records keeping is indisputable it is an ordinary and necessary component of virtually all business operations. Transparency and accountability can only be achieved if there is a policy that guides the management of records.
\end{abstract}

\section{Subject Areas \\ Information Science}

\section{Keywords}

Records Management, Accountability and Transparency, Information, Organisation

\section{Introduction/Background of Studies}

It is generally believed that the ability of an organisation or institution in managing its records could be a prerequisite to effective administration. [1] held the view that proper records management could help institutions to manage their information efficiently, fulfill their mandate, protect them from litigation, pre- 
serve their corporate memory and foster accountability and good governance. Records management is the effective storage and retrieval mechanism of information that aids an organisation in making decisions. Records are essentially the basic principles for the development of any institution. The manufacturing of computers and the advent of Internet connectivity have revolutionized work activities and have created new avenues for work and work practices. Thus the role of records and records management personnel has changed significantly in terms of information retrieval, creating, storing and dissemination of information.

Practicing proper records management leads to effective management because an institution's activities are based on access to the information contained in records. Competent record keeping is the key to the attainment of an institution's vision and mission, ranging from teaching, research, consultancy, innovation and service to the community.

Efficient records management provides the basis for accountability, transparency, protection of rights and entitlements, anti-corruption strategies, poverty reduction and effective management of resources. The keeping of records and storing of information in an institution have in the past few years become critical not only for historical purposes but also and more importantly for current and future managerial and policy development. Records have been used as tools and instruments to understand organisations and to use them as basis for improvement, comparison with other agencies and secure resources [2].

\subsection{Justification of the Study}

Records are significant assets in ensuring that the institution is managed effectively and efficiently and is accountable to its staff, students and the community that it serves. Searching for a document that cannot be retrieved is the biggest problem that affects many organisations and is time consuming for the person searching for it and the user. [3] stressed that good records keeping saves time since there is no hassle when searching for information. Lack of training in records administration and management is one of the major problems in protecting records.

Properly applied records and information generated by the organisation can be classified, organised in such a way that can be found quickly and used successfully to aid the decision process undertaken by the staff and management. Accidental and permanent loss of property is avoided when proper records keeping is maintained [4]. When records are managed according to a formal retention policy, it is easier to respond to an audit or litigation. Good records management saves time, effort, space, money and other resources. Properly managed records are easy to locate because they are well organised and labelled. Sound records management is therefore at the centre of increased accountability and good governance. It is one of the best weapons in fighting corruption and plays a vital role in the advancement of human rights and contributes towards 
ensuring sound financial management. Perhaps the most important pillar of good governance is accountability and transparency. Public officers should be accountable for their actions and for this to happen there must be evidence to clearly state who is responsible for what action, for example theft or loss of public funds. Such evidence which is always in the form of records is needed in case of recovery of lost and stolen monies or in case of court action. This clearly emphasises the immense importance of keeping records effectively and efficiently especially financial records. [5] and [6] underscored that reliable, timely and accessible records should make available information about administrative action such as resources received, committed or spent resources, which facilitate and simplify accountability. Records therefore should be managed in the same manner that the other organisational resources such as finance, and staff are managed. Effective record keeping is essentially the key to the attainment of institutional goals.

No organisation can operate effectively if it relies on memory alone to keep tract of every transaction. Records provide verifiable evidence of fraud and can lead investigators to the root causes of corruption. An organisation's records are a key instrument of effective administration and planning as the means by which the public and government hold that organisation accountable. Therefore records need to be properly managed to support the business of organisations. This situation justifies the need to explore the management of records in organisations and the extent to which it meets staff efficiency at work and the attainment of organisational goals.

\subsection{Research Significance}

The representational view of records is multidisciplinary and embraces a wide spectrum of understanding. [2] argued that the process for managing records is often linked to a living organism in that they are conceived and created, live and are used, became dominant and are retired, and die and are archived. This publication further maintained that records management provides a framework to enable these actions to be undertaken. It aims to ensure that records:

1) are present;

2) can be accessed;

3) can be interpreted;

4) can be trusted;

5) can be maintained through time;

6) will be disposed of as part of a planned system.

The study will help to fill in the gaps that were created in terms of proper records management. The study can be deposited in libraries, resources centers and documentation centers that can be used by researches and others in conducting workshops, seminars, conferences and for further consultation in writing articles.

Additionally, the study will pave way for organisations to prioritize the need 
to appoint a trained and qualified records manager who will champion the activities of records management at management level and influence management support. The study revealed the importance of records management as a significant tool in achieving organisational objectives. Records management must be a collective responsibility of all stake holders in the organisation. Records management strategy should be incorporated in all aspects of management function. Top management must be involved in each phase of the records management process. Records management functions must be embraced by top management to enhance effectiveness in all aspects.

\section{Discussion}

[7] highlighted that the essence of proper records management cannot be over emphasized. This is because records are indispensable to the efficient and economic operation of the organisation. They posit that records served as organisational memory by giving evidence of past events and basis for future actions. The aim of records management is to ensure that records are created, used, stored, and retired in an orderly and controlled manner. In contrast [8] argued that "it is now globally accepted amongst archives and records management professionals that the life cycle concept of records management is the most integrated and comprehensive approach to caring for records" (p. 184). [9] stated that records management is a specialised field that requires well trained personnel to effectively handle it. Staff/users relationship must be cordial; staff must ensure that users have easy access to records when needed.

According to [4] records management is the activities of a one man operation up to multi-national entity and the central departments of governments all have the need to keep good records as they provide evidence of the activities undertaken. PRISM maintained that the first thing to encounter in caring for records is the problem of management. Management using an organisation's resources to achieve specific goals through the functions of planning, organising, leading and directing. These four functions of management must be borne in mind when one studies the management of records.

In her publication "Value added records management: protecting corporate asset and reducing business risk" [10], discussed the value of records management in organisations. As litigation threats; government demands and office technologies changed how we do business, the author called on business management for fresh perspective regarding records management. He argued that the evolution from paper-based to multi-media business system contributes to a fragmentation and loss of control of those systems. An organisation will need to organise, integrate, and carefully manage its various information in order to harness their power. The book critically examines the changing roles of records management to support protect and add value to the organisation.

Records contain valuable information which is an essential input for the administrative, economic, scientific and technological functions of an organisation. 
[10], illustrated situations in which proper records keeping is necessary for a business to preserve its legal rights and to protect itself from undue harm and losses. If records are poorly managed it can lead to costly implications. Therefore management strategies must be implemented to prevent or minimise the risk of poor records management and its consequences. In order to provide better information at lower costs, the management strategies will help narrow the gap between the function's capabilities and its actual function in business. The importance of records protections is most fully understood and appreciated by those who have experienced losses from fire, tornado, and earthquake or computer disaster. Disaster victims, more capable of clearly visualising the real and potencies of loss from these unexpected emergencies, have faced the difficult task of producing the documentation necessary to received public relief.

[10] further asserted that every business has valuable and sensitive records and information. Valuable records are those that affect income and profit or that represent a tangible asset. Sensitive records are those which must not be disclosed indiscriminately to others, within or outside the organisation. One of the cardinal principles of records management is secrecy and confidentiality. Records are very sensitive and confidential, among which includes personnel records. Records that contain personal information of the individual must therefore be monitored and controlled. Staff must be aware that they are entrusted with the responsibility never to reveal information of personnel records. Staff must understand the ethical responsibility of working with and access to these records. Certain records have restricted access at the national archives, among which are personnel records. These records can only be released based on certain conditions. That is if the interests of access outweigh those of confidentiality, then the Director of the National Archives or other competent authorities will give judgment with regards to its access.

However the quality of records management in an organisation especially personnel records can affect the employee as well as his family in terms of pay, entitlements and job security. Employees or public servants who are involved in corruption or fraud or who fear for their jobs are unlikely to keep records. The author maintained that a well-designed records management system helps protect an organisation legally. Undoubtedly proper records keeping protect an organisation from litigation, but no matter how diligent a business tries to identify, understand, and comply with the law, it is inevitable that it will experience some type of government investigation or litigation during its time. Litigation by aggrieved parties cannot be ruled out. When records are managed according to a formal retention policy, it is easier to respond to an audit or litigation [11].

Obviously Proper records management will help protect the organisation legally especially during litigation, as there will be evidence in which the organisation can heavily rely on. Theft, fraud and corruption can easily be detected as all valuable information are recorded, this is particularly important especially when dealing with financial records. In the absence of clear, authoritative retention 
guidance, an employee may unknowingly destroy records that are relevant for litigation, government investigation or other legal matters, there by exposing an organisation to charges of spoliation (destruction) of evidence with intend to obstruct justice. Further in the absence of systematically developed retention policies an organisation will not be able to convincingly affirm that a specific record requested during discovery by the opposing party was destroyed in the regular course of business prior the commencement of legal proceedings. The effective management of records helps an organisation to demonstrate compliance with regulatory obligations and increase an organisation's efficiency by promoting the disposition of out of date items. Effective records management serves as an effective tool for administrative work; it helps in the day-to-day decision making of the organisation and even the survival of the organisation's decision making.

Without proper and accurate information a decision maker is never certain about the outcome of her decisions. Records management enhances accountability, business continuity, compliance and overall efficiency. The need for record keeping is indisputable, it is an ordinary and necessary component of virtually all business operations. They document an organisation's decisions, actions, transactions, and other activities. Records management concept and methods provide systematic, well developed approaches to records keeping operations that individual departments would otherwise performed themselves, without direction and, presumably with less knowledge, skills, and effectiveness. Thus the business case of systematic records management is based on its instrumental value for effective records keeping.

[12] writing on "Information and records management: documentation based information system," asserted that records management is a professional discipline that is primarily concerned with the management of document-based information system. The application of system and scientific controls to recorded information required in the operation of an organisation's business. The systematic control of all organisational records during the various stages of their life cycle: from creation or receipt, through their processing, distribution, maintenance, and use to their ultimate disposition. The authors maintained that the purpose of records management is to promote economies and efficiencies in record keeping. To assure that useless records are systematically destroyed while valuable information is protected and maintained in a manner that facilitates its access and use. Records keeping is a necessary but expensive activity. Records keeping costs are an important, if often unrecognised, component of an organisation's operating cost. Cost reductions have been an attainable objective of systematic records management for half a century. The earliest records management initiatives emphasised cost-effectives storage and retrieval of operating records in large corporations and government agencies. Thus cost reductions remain the principal motive for systematic records management for many organisations. The emphasis throughout this publication is based on one premise, 
that is, better records make better business. One significant area that the authors dwelt extensively is the reasons for maintaining an effective records management system in the organisation to:

1) control the creation and growth of records;

2) reducing operating cost;

3) improve efficiency and productivity;

4) assimilate new records management technologies;

5) ensure regulatory compliance;

6) minimise litigation risk;

7) safeguard vital information;

8) support better management decision making;

9) preserve corporate memory;

10) foster professionalism in running the business (pp. 8-11).

The authors further reiterated on the barriers to the development of excellent records management programmes in many businesses and government agencies. The following are the three reasons according to them:

1) records management programmes do not generate income. Although every organisation needs records management it is sometimes difficult to justify these programmes based on the return on investment they yield;

2) records management is not the organisation's primary business;

3) records management programme are usually discretionary (p. 15).

Although, these barriers can be minimised if the necessary measures are put in place. Effective records management programme is the basis in which organisations can generate income and achieve organisations success. It is evident that no organisation can survive without making records its activities. An organisation's decision making process or even its survival depends on records. Many organisations are beginning to realise that effective records management programmes are significant in achieving organisation success. While top executives often recognised the need for records management, they sometimes tend to see it as an administrative problem that is tangential to the over-all success of their business. Without controversy records management is not the priority of many organisations, and often relegated to secondary status in the mind of senior decision makers. Again records management is usually discretionary. Except in some government environments where formally organised records management programmes are mandated by statute. These programmes are always discretionary.

[12] further maintained that records serve as memory of business. They document the information needed for operating the firm. For example management policies are developed and recorded to furnished broad guidelines for operating a business. Each department (marketing, finance, and human resources) bases its entire method of operations as open records. The authors argued that usually, records are used and retained because they have one or more of the following values to a firm: 
1) Administrative value: help employees perform office operation within the firm. Example of such records includes policies, manuals, handbook, and organisation chart;

2) Fiscal/tax value: may be used to conduct current, or future financial or fiscal business. Fiscal records can document operating funds or serve tax audit purposes, such as tax returns and records of financial transaction such as purchase and sales orders, invoices, balance sheets and income statements;

3) Archival/Historical value: records can also have historical or archival value. They furnish the records of an organisation's operations and major shifts of direction over the years. Minutes of meetings, the corporate charter, public relations documents and information on corporate officers all fall into this records category;

4) Legal value: provide evidence of business transactions. Example of such records include contract, financial agreements that are legally binding, deeds to property owned, and article of incorporation (p. 6).

From the aforementioned it is evident that records must be retained as long as they possess these values to the organisation. The administrative value of records is the length of time it may be needed or used within the organisation. This value is set by the department head who is responsible for the copy of record, although the needs of other departments using the records must be considered. In addition to an overall retention value, the departments head should also sets a period of active records use. For the period the records should be kept in the office; then it should go to the record centre for the remainder of the retention period. For most records the active period should not exceed two years, and it may be substantially less. There are exceptions such as an employee's personnel file, which remain active as long as the employee is in the organisation. Administrative value helps employees perform office operations in the firms. Examples of such records include policy and procedures manuals, handbooks and organisation charts.

The fiscal values pertain to financial matters in general: such records are usually required for audit purposes. In a typical organisation, approximately half of the records are financial in nature, and many of these have tax implication. Financial records should be retained for a minimum of the Internal Revenue Service Statutes of limitations (generally three years from the date the return is filed or due). Fiscal value can document operating funds or served tax audit purpose. Examples of this type of records include tax return and records of financial transactions such as purchase and sale orders, invoices, balance sheet and income statement. Records and information relevant to any potential, current, or past litigation or government investigation are considered valuable. Legal records provide evidence of business transactions. Records management ensure that institutional records of vital historical, legal and fiscal value are identified and preserved, and that non-essential records are discarded in a timely manner according to established guidelines and legislation. 
Records management saves space by removing inactive records from busy, crowded offices where space is at premium and sending them to storage and by ensuring the timely destruction of records that are no longer used. It is also important to note that inactive records sent to the national archives might be needed back by the organisation; these records can be re-used to create new knowledge for the benefit of both individual and the organisation. In determining how long to retain records, their capacity for re-use is important. Many are simply kept as evidence of transactions. Records are managed according to the retention schedule. Once the life of a record has been satisfied according to its predermined period, then it is authorised for final disposition, which is to destroy or onward transmission to the national archives for permanent preservation based on specific archival values such as scientific value, research value, physical value, archival or historical value, administrative or operational value, enduring value, informational value, fiscal value and financial value among others. Many organisations lack the effective procedures, policies for the systematic control of their recorded information. Thus some records are kept for so long without subjecting it for the procedure for effective disposal. Some records have more value than others, and the sensitivity of certain records may cause harm when they are disclosed to the wrong parties. Organisations produce lots of records, if these records are not properly managed it will lead to waste of space and will have a great implication on cost and staff.

Similarly [13] in their publication "Managing records: a handbook of principles and practice" discussed the principles of records management and its practical implication in contemporary organisation. According to them poor records management does not exploit the value of the records, many records are lost and they are not categorised in a proper way. Poor records management can further destroy an organisation irreparably. Poor records management invites unacceptable risk because corporate records have enormous credibility with respect to the information they contain. In organisations where records are poorly managed, records will often be inadequate for the purposes for which they are needed and some records will probably be destroyed prematurely and others retained unnecessarily. They further maintained that excessive retention of records will give rise to retrieval difficulties as well as wasted resources; a failure to create adequate records or maintain them appropriately will probably have more serious consequences. Increasingly organisations are recognising the benefits of well-managed records and are implementing programmes to ensure the right records are created and retained. Shepherd and Yeo further reiterated about the organisational context, where records managers are specialists in records management but rely on the co-operation and participation of all employees. Their publication expounded on the concept and practice of records management, for organisational staff who have responsibility establishing or reconstructing a records management programme. For this to be fulfilled there is the need for both staff and managers to understand the context of their work at a number of 
different levels. They need knowledge of the records that are produced, the organisational activities that generate records and the system used to control them. In addition they should have a thorough understanding of the organisation itself and how records management contributes to its objectives. Records management programmes vary from one organisation to the other, but typically comprises a number of elements. These, according to [13] include:

1) settings and monitoring policies and standards for records management throughout the organisation;

2) designing and implementing records management system;

3) Informing and educating staff about records management (p. 22).

In a smaller organisation the operation of the programme is likely to be the responsibility of a records manager working alone. A larger organisation is likely to require a records management unit with a number of staff in order to operate effectively. The need for effective records management in an organisation gives priority to proper records management. What is needed is the development of records management capacity at all levels of responsibility. Consequently there is the need to have a records manager at the top of the organisation level; focus must be put on executive support and champions. The need to have an effective records manager is essential for every organisation. The efficiency of the staff in keeping proper records depends on the personal qualities of the records manager. He should be capable of performing his duties as a leader, directing the work force which includes continue decision making and translating it in order and instruction. Records have always been an organisation's central resources; without them the organisation simply cannot function effectively. With good selection, training and encouragement many more people can play valuable records management roles. The authors maintained that records must be possessed the following.

1) content: a record must reflect the facts about the activity. For reliability a record should be accurate (the fact should be correct and complete) everything of significance should be recorded;

2) context: a record must be supported by information about the circumstance in which it was created and used. Records cannot be fully understood without adequate knowledge of the activity that gave rise to them, the wider function of which that activity forms part, and the administration context including the identities and role of the various participants in the activity. Contextual information must therefore be captured in the records themselves or in the systems that are used to maintain;

3) structure: records and records systems must reflect the relationship between their constituent parts. The structure of records forms a link between content and context, structure organises content in such a way as to denote context, and thus contributes to users' understanding of records (pp. 10-11).

In his work "Records and information management fundamentals of professional practices" [14] stated that records management is a specialised business 
discipline concerned with the systematic and control of recorded information which include any and all information created, received, maintained or used by the organisation in accordance with its mission, operation and activities.

[14] believed that the true value of records management essentially is three fold. A proper records and information management system can enable your business to:

1) reduce operating cost;

2) minimizing risk;

3) increase revenue.

Records management can help reduce not only operational cost but all cost incurred by the organisation; it allows organisations to ensure that its staff had complete access to accurate information in a timely and cost-effective manner. Efficient records keeping contributes to profitability by lowering the cost of doing business. The consequences of spending too much time searching for misplaced records can be very severe; thus it is important to have a well-designed filing system that can facilitate the creation, retrieval and disposal of records. Implementing effective records management system in an organisation reduces risk, most specifically the risk associated with litigation and potential penalties. Proper records keeping according to [14], increases revenue, not only revenue but also serve as a competitive advantage, enabling the organisation to maintain its competiveness in the global business environment it helps in effective and faster decision making.

Records are essentially for effective and efficient administration, but if poorly managed they become a liability, hampering operations and draining resources [15]. Records management adds value to the daily functions of staff in an organisation. Records management is needed in order to minimise risk and provide efficient and transparent business process. If public officers keep their records right, the records would always be there to show the situation as it is. This further emphasises the need to keep records effectively as it is the only way that organisation can make effective decision in achieving organisation's objectives. One cannot talk about good governance, democracy and rule of law when records are not properly kept. The importance of records management is highlighted by the needs for evidential proof of activities in account or dispute. Thus organisations and individuals cannot afford to downplay the art of proper records management. The purpose of records management is to use records for maximizing the value of the organisation, vision accomplishment improving performance and support the success of the organisation. Effective records management starts from the top; that means an organisation's leadership has to understand the need for records management, and put support behind it. In any organisation, managing records should be a strategic function, with a continuing programme that is effective across the organisation as a whole.

The benefits of records management in an organisation include:

1) records management reduces cost, especially space cost by ensuring that 
inactive records are disposed of and also save time and efforts of employees;

2) it ensures regulatory compliance;

3) reducing labour requirements for creation, organisation retrieval, and dissemination of recorded information;

4) helping in ensuring that records that are no longer in active use are subjected to effective procedures for the identification of those which can be destroyed at the end of the agreed retention period and those which should be transferred to the national archives for permanent preservation;

5) records provide a reliable, legally verifiable source of evidence of decisions and actions. They document compliance or non-compliance with laws, rules and procedures.

In "Electronics records management training package", [16] expounded on the use of Information Communication Technology to facilitate effective records keeping. The author maintained that the use of ICT helps to facilitate effective records keeping. For instance, educational institutions may be unable to defend themselves against inappropriate claims of their products or services or its employee's, actions and in the absence of adequate students records business operations may be compromised and rights of students impaired .The poor use of ICT in enhancing information flow in organisations is mainly due to inadequate ICT facilities and lack of enough computer skills among employees. Thus it has a negative impact in the creation, retrieval and use of records, most specifically, in the use of electronic records [17]. Managing accurate and up-to-date information is critical in the digital information era; organisation needs employees who are skilled in ICTs and are abreast with the latest technologies, to create, store and retrieve information effectively and efficiently [18].

Similarly [19], in their article "Developing countries' challenges and threats towards a realistic plan," stated that the discipline of records management has been traditionally viewed with little significance. Records management has not been the priority of many organisations. Poor records keeping system are barriers to institutional, legal and regulatory reform; and anti-corruption strategies; poverty reduction and economic development. Effective records management provides information required for proper functioning of organisations. On the other hand poor records management can be risky to organisations. Organisations that manage their records well reap immediate benefits in terms of being able to utilise all available information resources for competitive advantages. [19] further observed that Information and Communication Technology (ICT) has expanded and presented opportunities for records keeping in developing countries; for instance, it has enhanced retrieval system and online search facilities. The authors dwelt on the constraints faced by developing countries in keeping proper records, such as inadequate resources, poor infrastructure, among others. The introduction of ICT into records management compounded this situation and make records keeping practice in many African countries to be different from the methods they have been practicing. Thus the role of records 
and records management has changed significantly. The relationship between ICTs and records management is quite essential. ICTs and records management are both concerned with the creation, storage, accessibility and security of digital information, thus records management should move along with the current trend of ICTs.

The aim of both records management and ICTs is to support, protect and enable the business of the organisation in a cost effective manner. As stated by [20], in their article the "Benefits of electronics records management system: a general review of published and some unpublished cases," the basic benefits that are easily observed in an organisation are how the work is done more easily because the effort needed is less; the work is done more quickly; the quality of services is increased; and it is easily transparent afterwards. The orderly and the efficient flow of information enable to perform its mission successfully and efficiently. This then means the management of records should be accorded priority in any organisation. Effective records keeping helps in preserving the organisation knowledge and safeguard important information of the organisation as it has enduring value.

According to [21], the positive benefits of electronic records management in the context of enterprise content management, maintaining good records management is an essential part of business and is connected to financial management and human resource management. Human resources policies like training and development, rewards and recruitment are likely to impact on the way staff manage records in an organisation. Human resources are the most valuable assets of an organisation and any policy affecting them are likely to impact on how effectively services are delivered especially in records management. With proper records management, organisations can use information contained in records to solve problems and make decisions ranging from financial records, disciplinary actions, transfers or termination. Fraud, corruption, and theft will be easily detected. Human resources management documents the contractual relationship between the employer and the employee and the employee's career history throughout the organisation. Human resource manage the most important resources of the organisation that is the people its serves. They maintain records at all levels of the organisational structure including their physical offices. These various locations have implications for the duplication of records and sharing of information with employees. Thus effective records management is necessary at all levels of the organisation. The key to administrative advancement is the effective caring for records. The effective keeping of information in an organisation leads to an organisation's success as effective decision making largely depends on records. Good records keeping and management ought to be taken as vital responsibility by institutions or organisations' authorities because of the significant role it plays in the day-to-day running of organisations. Good records management helps us to identify records of historical importance which are kept as archives. 
[21] further maintained that records

1) ensure that an organisation conducts its business in an efficient and accountable manner;

2) deliver services consistently and equitably;

3) document its policies, decisions and outcome to stakeholders and regulations;

4) meet its legislative and regulatory requirements;

5) protects corporate interest as well as the right of the employee including audit;

6) protect itself in litigation;

7) function in a financially and ethically accountable manner;

8) protect corporate interest as well as the rights of the employee;

9) provide continuity of operation in an emergency or disaster and maintain its cooperate and institutional memory (p. 298).

Proper records management ensures that comprehensive and complete records are created, inventoried, indexed, kept in a secure storage, retrieved when required to conduct business, and ensure that the right records are disseminated to the right person at the right time. Effective records management system provides information required for the proper functioning of an organisation. On the other hand poor records management can be risky to the organisation. An institution where records are poorly managed, the flow of records through the life cycle is retarded. Information can only be found if there are well managed records. It is necessary to provide high priority to records management to avoid organisational problems that may arise owing to poor handling of office records. As organisations continue conducting their business they generate records on a daily basis which need to be reduced lest they become voluminous and unmanageable. In instances where queries or controversial files disappear and with the gab in the filling cabinet conspicuously noticeable, it may even be difficult to locate some records a few years later. Thus records cannot be left in offices whose mandate is not records management as there might not be proper control measures to secure records from theft or loss. A good management system ensures that records management is integrated whether the records management is centralised or decentralised. Records are the indispensable foundation of accountability process. Without reliable and authentic documentary evidence underpinning all essential accountability process, government, civil society and private sector cannot ensure transparency, guarantee accountability or allow for exercising of good governance [22].

[23], discussing records in public sector organisations as assets Shepherd postulated that records which are managed as part of an appropriate records management programme will help the organisation to conduct business in an efficient, and accountable manner, deliver service consistently, support managerial decision making and transparent policy formulation and ensure continuity in policy execution, management and administration. Many organisations do not 
yet have a formal programme of records management but increasingly they are recognising the benefits of well managed records and the consequences of inadequate records system. The author maintained that effective records management entails establishing a physical and intellectual control of records that are entering the records system. This is done through entering all records as they enter the system, locating them by where they can be found quickly by means of classification schemes, filing index, and catalogue. Records developed and maintained in the normal course of business acquire a special evidentiary status long recognised in the law.

Establishing records management and maintaining an effective programme requires specialist expertise, the tools and process alone cannot achieve the goal of an effective records management programme. People are responsible to carry out the operations. Thus the concepts, skills and techniques of records management for organisational staff who have responsibility for setting up, maintaining or restructuring a records management programme is fundamental. If organisational staff do not understand the concepts, skills, and techniques of records management, then the goal of records management programmes will not be achieved [24]. In order for records management programmes to succeed there should be some level of awareness of the procedures, policies and standard governing the management of records.

[2] bulleted the symptoms of poor records management as follows:

- inadequate information;

- duplication of records not knowing the least version;

- complex filing system;

- outdated information;

- lack of proper security;

- waste of time searching for information when they are not properly organised;

- waste of space due to unwanted storing of records;

- in-conducive working environment;

- poor decision making;

- legislative requirement is adhered to;

- difficult to control records;

- ubiquitous records.

Proper records management fosters accountability, transparency and good governance. Organisations might find themselves embarrassing if requested records are not found as a result of poor records system. [25] "Managing records as basis for effective service delivery and public accountability in development" underscored the importance of records as they document fundamental rights and obligations. The need for Freedom of Information (FOI) is quite essential, FOI is seen as a key in endangering trust between government institutions and citizens and strengthening the democratic process. However, FOI could only succeed if reliable records exist and the information they contain can be accessed when 
needed. Access to reliable, accurate and timely information is a fundamental right to individuals. Information is a basic right and every individual needs to have access to information and for this to happen there must be proper records keeping at all levels of the organisation. Without proper records keeping fraud cannot be proven; meaningful audit cannot be done; and government actions are not open to review.

Poor records management creates an opportunity to commit fraud and corruption. Sound records management is therefore necessary to root corruption and malpractice which increases detection of fraud and corruption. National and international efforts to reduce poverty, improve services, control corruption and strengthening democracy depend on reliable authentic records. Therefore a clearly established legal framework for records management administration is required. Records are consulted as proof of activities by senior management, auditors, and concerned citizens or by any one inquiring a decision, process or the performance of an organisation or individual. Poor records keeping practices hinder accountability and transparency of organisations. Good records keeping saves time since there is no hassle when searching for information. Records support decision making, improve accountability and transparency [25].

Effective records keeping helps institutions or organisations to conduct business and deliver services in a consistent and equitable manner. While a Company's records management is not profit centred, handling records incorrectly can lead to financial penalties or litigation. Keeping good records helps companies protect institutional memory as well as maintain evidence of activities, transaction and decision making. An effective records management system can save money on storage and improve an organisation's efficiency. Effective records keeping is essential in every organisation. For instance in academic institutions , poor records keeping can lead to inability to graduate students whose grades are misplaced, cancellation of certificates and transcripts due to inaccurate grades or wrongly recorded grades. Managing records in educational institutions is important because good records that are accurate, comprehensive and authentic store important information needed for administrative, historical and evidential purposes.

Practising proper records management leads to good management because an organisation's activities are based on the information found in records. Records are basic tools of government administration. They provide information for planning and decision making, from the foundation for government accountability, and are often subject to specific legal requirements. Proper records management helps an organisation get most out of its records. It also helps limit cost and risks that can come with poorly managed records. [26], in his article on "The contribution of proper records keeping towards auditing and risk mitigation: Auditor General of South Africa's Perspective," stated that records management is an enabler because without it things like auditing and financial management will not be possible. To achieve this objective records must bear the 
following qualities:

1) authenticity: records should be authentic, provenance proof of origin and the chain of custody through which it had passed;

2) completeness: records should include all relevant context and contextual information;

3) reliability: records must be reliable, factually correct and accurate. It is important that the content of the records can be relied upon as an accurate representation of the transaction it is documenting;

4) fixity: once declared as a record its content should no longer be altered or changed in any way. It is in this way that its evidential value is preserved.

Records should have qualities of integrity and usability as well. The authenticity and integrity of records need to be guaranteed overtime so that users can be confident that records are genuinely and trustworthy and that no illicit alteration have been made to them. Records must be usable they must be accessible to authorise users and provides sufficient evidence of the context of their creation to support users understanding of their significance. Records created within the organisation should be reliable and accurate in their content. Records demonstrate and confirm the decisions taken; the action carried out and the reason for such action; they support policy formulation and management of decision making; protect the interest of the organisation, the right of the employees, clients and citizens; and help the organisations to conduct their business and deliver their services in a consistent and equitable way. Records are important because of the information they contain that is essential for every activity carried out in the organisation. These include:

1) reducing labour requirements for creation, organisation, retrieval and dissemination of recorded information;

2) helping in ensuring that records that are no longer in active use are subjected to effective procedures for the identification of those which can be destroyed at the end of the agreed retention period and those which should be transferred to the national archives for permanent preservation;

3) records provide a reliable, legally verifiable source of evidence of decisions and actions. They document compliance or non-compliance with laws, rules and procedures.

Thus every organisation needs to conduct its activities and this can only be achieved by creating records. Proper records management underpins policy formulation, decision making, protects interest of an organisation and protect the rights of employees. Records are valuable assets that need to be protected. Decision makers need records and archives. When making decisions the speed with which records are made and the quality of the decisions made depend on the availability of the information which enables all relevant factors and issues to be considered before a decision is made. It is evident that without records, all organised administration will quickly collapse. Records and more specifically for the information they contain are vital resources that an organisation needs to 
conduct its operation effectively. An organisation's records preserve its corporate memory.

[27] further examined the purpose and scope of records management as a business discipline. The author first gave a summary of the conceptual foundation of systematic records management. Although corporations, government agencies, and other organisations have been creating and maintaining records for centuries, the quality, variety and complexity of recorded information have increased dramatically, even exponentially, in recent years. Contributing factors include:

1) the expanded scope and increased complexity of government operations at all levels;

2) the expanded scope and increased complexity of commercial and industrial enterprises, including mergers and acquisitions that have created large multinational entities with operations in dozens or even hundreds of countries;

3) increased government regulations and their associated records keeping requirements, which affect the regulatory agency as well as the regulatory entity;

4) a large white-collar work force that depends on recorded information for the completion of assigned tasks, management analysis and decision-making, project management and other purposes;

5) the increased prominence and economic significance of information-intensive service industries such as banking, insurance, management consulting, litigation support, and other healthcare;

6) The widespread implementation of computers, high-speed printers, photocopiers, data communications, and other technologies that can quickly generate large quantities of recorded information in a variety of formats (p. 3).

The author maintains that records management principles and practices have developed in response to the increased pervasiveness of information-related activities that characterise modern work environments and the corresponding need to systematic approaches to records keeping requirements. However this development has significantly changed the role of records and records management personnel. Records, concepts and methods have been expanded and refined considerably. A more active approach to records management is required and emphasis must be placed on the retrieval process. The author further gave an overview of the most important components of records management programme and an evaluation of records management's contribution to organisational effectiveness. This principles unarguably provides a firm conceptual foundation for the development and implementation of effective records management initiatives. [27] asserted that systematic records management is principally concerned with five aspects of information:

1) determining how long records need to be kept to satisfy all requirements to which the records are subject;

2) ensuring compliance with records keeping laws and regulatory in all locations where an organisation has business operations; 
3) managing inactive records in a cost-effective manner;

4) organising active records for retrieval when needed;

5) protecting recorded information that supports mission-critical business operation (p. 11).

These aspects apply equally to paper and non-paper records. The author concluded by expounding on the relationship between records management and other Information Management disciplines and activities such as Computing; Telecommunication; Knowledge Management; Library Science and Archival Administration. Collectively these disciplines are involved in the systematic management of information resources. Their relationship to records is complementary rather than competitive. The management of records is essential in achieving organisation goals, and it is only through the effective management of record were in organisation goals can be achieved. The management of records entails establishing physical and intellectual control over records that are entering the system. This is done through registering each records as it enters the system, locating it where it can be found easily by means of a classification scheme, placing it into files that are properly titled and by indexing the information in the records. [28] contended that good records management ensures that an institution meets its records keeping requirements by ensuring that it captures and preserves the evidence required to establish its activities and existence.

Every organisation has its needs for records and information. Records are necessary for planning, resources management, and proper management of daily activities and business transactions. Records serve as memory of an organisation. They document the information needed for operating the firm. The success of any organisation depends on effective records management practice that ensures the right records are available at the right time for effective business operation. Successful decision making and problem solving is made possible through the availability of reliable and complete records. The importance of records management in today's world cannot be overemphasised; records and information are the life blood of every organisation and they are the basis in which decisions are made. The purpose of records management is not only to manage records but also to use them for maximizing the value of the organisation, mission and vision accomplishment, and improving productivity. Without a records management policy, a university has no foundation or guide for the effective management of records, meaning that there is no framework for supporting documents such as procedures, business rules and disposal schedules [29].

\section{Conclusions}

Records keeping is integral to the function of any business, as it enables the control of one of the most important resources in any organisation (information resources). The design and implementation of a policy on records management is prudent. A policy must be formulated for regulating records management activities. Records management rules and regulations will guide records manage- 
ment activities and ensure that all records created and received are recorded in an appropriate manner. The existence of a records management policy will guide the management of records and provide the operational basis for effective management. Management must employ the principle of accountability, transparency, integrity and protection to privacy. It is the responsibility of staff to ensure that users records are highly protected and monitored. Staff must know that they are entrusted with the responsibility to monitor and protect records. The life cycle concept of records management must be applied at all levels of the organisation. The principal reason for applying the life cycle concept of records management is to ensure that the records being created and held by the institution are managed and maintained properly. [30] suggested that keeping active records and semi-active records could pose serious storage and retrieval problems. Active and semi-active records must be separated for effective storage facilities.

Additionally, the need to develop an appropriate model for the preservation of records is necessary. Adequate storage and security of records must be provided. Electronic records management system should also be provided.

\section{Recommendation}

The following recommendations are made to enhance proper records keeping in organisations:

- The need for the implementation of a disaster recovery plan. This is necessary to prevent or minimise events of natural disasters such as fire, earthquake or flood. In the absence of a disaster recovery plan it would be impossible to recover loose documents. Hence Records must be well secured; security measures help reduce the number of records that are being tampered with which can jeopardise institution's wellbeing and interests.

- The automation of records in organisations must be implemented. This is significant to ensure that users have access to the right records at the right time and in the right manner. Electronic storage offers an advantage of storing large number of records. It saves time, more cost effective; and most importantly records can easily be retrieved.

- Adequate filing system should be adopted for the filing of records so that they can be retrieved easily.

- Poor records management in most organisations can be attributed to the incompetence of staff from performing their duties effectively. Hence capacity building for staff must be initiated. Records management staff must be trained and retained especially in ICT application. Training could be in the form of seminars, conferences, short courses and workshops to develop staff's skills. This will help staff acquire new skills with regards to proper documentation and safe keeping of files. Proper infrastructure must also be put in place for the effective management of records.

- Provision of adequate funds for the management of records is essential. Top 
management must ensure that adequate funds are provided for records management activities.

- Finally, there is a need for further research to be conducted on generating, using and managing records in organisations, disaster management of records as well as ICT applications and records management.

\section{Conflicts of Interest}

The author declares no conflicts of interest.

\section{References}

[1] Obi, S. (2014) Records Management in Higher Educational Institution in Bayelsa State: Implication for School Administration. http://www.docplayer.net

[2] ACARM (Association of Commonwealth Archivists and Records Managers) (2007) Records Management Guide. University Press, London.

[3] Ngoepe, M. (2004) Accountability, Transparency and Good Governance: The National Archives and Records Service in South Africa's Role in Helping Government to Better Service Delivery to the South Africans. South Africa Press, Pretoria.

[4] PRISM International (2016) "Why Records Management"? International Conference Paper, Webinar.

[5] Thurston, A. (2005) Transparency in Government in the Electronic Environment; Accountability Forum 2006. Fostering Truth and Transparency though the Information System. World Bank Poverty Reduction and Economic Management Network.

[6] Basil Iwhiwhu, E. (2005) Management of Records in Nigerian Universities: Problems and Prospects. The Journal of Electronic Library, 23, 42-68.

https://doi.org/10.1108/02640470510603741

[7] Tagbotor, D.P., Adzido, R.Y.N. and Agbanu, P.G. (2015) Analysis of Records Management and Organizational Performance. International Journal of Academic Research in Accounting, Finance and Management Science, 5, 1-6. https://doi.org/10.6007/IJARAFMS/v5-i2/1557

[8] Akussah, H. and Asamoah, C. (2015) Management of Public Sector Records in Ghana: A Descriptive Survey. Records Management Journal, 25, 183-196. https://doi.org/10.1108/RMJ-10-2014-0044

[9] Tsabedze, V., Mutula, S.M. and Jacobs, D. (2012) Records Management in Government of Swazilan. ESARBICA Journal, 31, p. 48.

[10] Sampson, K.L. (1992) Value Added Records Management: Protecting Corporate Asset and Reducing Business Risk. Quorum Books, New York.

[11] Taylo, M. (2000) Records Management at Tertiary Institution in the SCECSAL Region at the Dawn of the New Millennium. In: Chisenga, A., Chitambo, A. and Onyango, F., Eds., Information 2000: A Vision for the SCECSAL Region, Namibian Information Workers Association, Windhoek, 239-245.

[12] Robek, M.F., Brown, G.F. and Stephens, D.O. (1995) Information and Records Management: Documentation Based Information System. 4th Edition, McGraw-Hill, New York.

[13] Shepherd, E. and Yeo, G. (2003). Managing Records: A Handbook of Principles and Practice. Facet Publishing, London.

[14] Saffady, W. (2004) Records and Information Management Fundamentals of Profes- 
sional Practices. ARMA International, Leneda.

[15] Norris, Thomas D. (2002) The Seven Attributes of Effective Records Management Program. New York Archives, New York.

[16] Hare, C. (2004) Electronics Records Management Training Package. Northumbria University, London.

[17] Kabel, N.A., Zhou, J.Y., Zotoo, I.K. and Su, W.C. (2021) Electronic Records Adoption in Archive Management in Djibouti's Academic Libraries: Barriers and the Role of Knowledge Sharing. Open Access Library Journal, 8, 1-15.

[18] Buchanan, S.A., Stratton, C., Sun, Y. and Chaudhary, A. (2017) Survey Research on Tasks and Competencies to Inform Records Management Education. Records Management Journal, 27, 2-18. https://doi.org/10.1108/RMJ-11-2015-0041

[19] Tale, S. and Alefaio, O. (2005) Records Management in Developing Countries Challenges and Threats-Towards a Realistic Plan. ACARM Newsletter, Issue 37, Winter.

https://www.fichier-pdf.fr/2011/03/18/37-6-records-management-in-developing-co untries-challenges-and-threats/

[20] Johnston, G.P. and Bowen, D.V. (2005) The Benefits of Electronics Records Management System: A General Review of Published and Some Unpublished Cases. Records Management Journal, 15, 131-140. https://doi.org/10.1108/09565690510632319

[21] Timothy Spere, J. (2005) The Positive Benefits of Electronic Records Management in the Context of Enterprise Content Management. Government Information Quarterly, 22, 297-303. https://doi.org/10.1016/j.giq.2005.02.003

[22] Casadesus de Mingo, A. and Cerrillo-i-Martinez A (2018) Improving Records Management to Promote Transparency and Prevent Corruption. International Journal Management, 38, 256-261. https://doi.org/10.1016/j.ijinfomgt.2017.09.005

[23] Shepherd, E. (2006) Why Are Records in the Public Sector Organization Assets? Records Management Journal, 16, 6-12. https://doi.org/10.1108/09565690610654747

[24] Mantangira, V., Katjiveri-Tjiuoro, M. and Lukileni, N.H. (2015) Establishing a University Records Management Programme: A Case Study of the University of Namibia. Journal for Studies in Humanities and Social Science, 2, 103-117.

[25] World Bank (2008) Managing Records as Basis for Effective Service Delivery and Public Accountability in Development: An Introduction to Core Principles for Staff of the World Bank and Its Patterns. World Bank, Washington DC.

[26] Bhana, P. (2008) The Contribution of Proper Records Keeping towards Auditing and Risk Mitigation: Auditor General of South Africa's Perspective. Paper Presented at the 3rd Annual General Meeting at the South African Records Management Forum, Midrand, 10-11 November 2008.

[27] Saffady, W. (2011) Records and Information Management: Fundamental of Professional Practice. 2nd Edition, Arma International, Kansas.

[28] Adu-Oppong, A.A. and Asante O. (2014) An Examination on Records Management at the College of Technology Education Kumasi Education. International Journal of Development, 2, 171-183.

[29] Barata, K., et al. (2016) From Accounting to Accountability Management: Managing Financial Records as a Strategic Resource.

http://www.irmt.org/documents/research_reports/accounting_recs/IRMT_acc_rec_ final.PDF 
[30] Wema, E. (2003) Problems of Managing Semi-Active Records in Instituttions of Higher Learning: The Case of University of Dar es Salaam. University of Dar es Salam Library Journal, 5, 46-56. https://doi.org/10.4314/udslj.v5i1.26593 